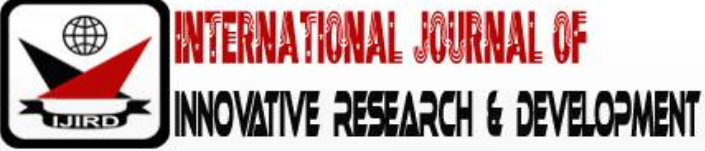

ISSN 2278 - 0211 (Online)

\section{Determinants of Child Labour in Cameroon: Taking into Account Non-Linearity of the Incomes and the Space Dependence}

Célestin Chameni Nembua
Full Professor, Department of Quantitative Economics
University of Yaoundé 2-Soa, Yaoundé, Cameroon
Christophe Kana Kenfack
Head, Department of Division in Charge of Applied Research
National Institute of Statistics, Yaoundé, Cameroon
Jean Faustin Kaffo
Researcher, Laboratory of Analysis and Research in Mathematical Economics (LAREM)
University of Yaoundé 2-Soa, Yaoundé, Cameroon

\begin{abstract}
:
Based on the Third Cameroonian Survey on Households of 2007 present research examines the assumption of non-linearity of the impact of the household's incomes per capita on the child labor and the econometric estimate appropriateness taking account the space dependence of the observations. The multilevel analysis with the income taken in "splines" reveals the nonlinearity of the incomes per capita of the households located below the threshold of the first and second quintiles and verify the Basu's "axiom of luxury". When the incomes of the adults located below the threshold of the first quintile of the distribution increase by F CFA 10 000, the rate of variation of the incidence of the child work decreases by a multiplicative factor of 1,016 the relative risk being of 1,022. The space dependence is correctly taken into account by the macro econometric model spatially autoregressive, which confirms also non-linearity. Thus the significant reduction of the child work depends on the increase in incomes of adults in the poorest households.
\end{abstract}

Keywords: Child labour, Determinants of Child labour, Spline Regression Models, Multilevel Modelling, Spatial Econometrics, Cameroon

\section{Introduction}

At the international level, the two main standards that reference in the field of "child labour" are Conventions No. 138 and No. 182 of the International Labour Organisation (ILO). The first concerns the minimum age - 15 years - for admission to employment, and the second focuses on the worst forms of child labour. Cameroon has ratified several international rights in the fight against child labour, among which the above conventions. There are two instruments at national level to identify the phenomenon of child labour. They are the Law No. 92/ 007 of 14 August 1992 on the Labour Code in Cameroon and the Decree No. 17 of 27 May 1969 related to Child Labour of the Ministry and social laws. The Labour Code establishes the general framework of work: minimum age for employment - 14 years - and work schedules. The order defines a number of activities or hazardous occupations prohibited for children and it defines the environment and unacceptable conditions for children. In this study, child labour means any activity carried out for at least an hour against income in cash or in kind during the last seven days by individuals of Unit 5-17 [National Institute of Statistics (INS, 2008)]. Despite all these raised instruments, this scourge continues. In fact, the National Report on child labour in Cameroon reveals that among 5,999,053 children 5-17 years (41 percent) 2,441,181 children are concerned.

The recent renewed interest in the theoretical and empirical literature inherent in child labour in developing countries highlights among the diverse factors of supply and demand, the role of household income, including the impact of poverty. For this purpose, the theoretical approach of Basu and Van (1998) is probably one of the most adapted to the context of developing countries to understand the decision of children's participation in the labour market (Lachaud, 2008). Because the model is based on two assumptions one hand, the "luxury axiom" indicates that the economic activity of children prevails only if the household has a lower standard of living to a critical threshold. Thus, leisure and education of children are luxury goods, and parents are altruistic. On the other hand, the "substitution axiom" states equivalence, a correction factor close, working adults and children. Therefore, the household poverty is a fundamental determinant of children's participation in the labour market. In this regard, Basu and Van specify a labour supply curve decreasing gradually as the standard of living of the household improves. 
The nonlinearity of the relationship between household income and children's participation in the labour market seem to be insufficiently discussed (Lachaud, 2008). In this respect it wasn't analyzed in the National Report on child labour in Cameroon. It is the same of the impact of the spatial dependence of the participation on the labour market. It is noted in the literature that generally the effect of income on child labour is apprehended by the sign of its coefficient (Diallo, 2001 and Lachaud, 2008) in econometric models all else equal their sign gives only the direction in which the income influences the chances of a child to participate on market work. However, it is reasonable to expect that the impact of household's income per capita on child labour is not the same for all income groups (quintiles). Moreover, the economic activity status of a child may be dependent on the proximity of the residential environment with an urban center. With this in mind, several questions arise: Are there any non-linearity of the impact of income on child labour? Is there spatial dependence of observations?

Based on the third Cameroonian Household Survey of 2007, this research examines first the hypothesis of nonlinearity of the impact of adult income on child labour in Cameroon. Then it examines the appropriateness of econometric estimates taking into account the spatial dependence of observations. The theoretical and empirical context is discussed in Section 2, while the data structure and methods of analysis are presented in Section 3. Sections 4 and 5 are devoted, respectively, to the teachings of the multilevel micro-econometric approach and spatial macro econometric approach. Finally, Section 6 concludes the research.

\section{Literacy Review}

Present research on child labour determinants is mainly justified by three elements of analysis. Initially, the recent renewed interest of the theoretical and empirical literature on child labour in the developing countries highlights, among the diversity of the factors of supply and demand, the role of household's incomes, in particular the incidence of poverty. First of all, the theoretical approach of Basu and Van (1998) is appropriate for developing countries to understand the decision of children work (Lachaud, 2008). Indeed, the model is founded on two assumptions. On the one hand, the "axiom of luxury" indicates that the economic activity of the children prevails only if the household has a standard of living lower than a critical point. On the other hand, the "axiom of substitution" stipulates equivalence, a correction factor close, of children and adult labour. Consequently, household's poverty is a fundamental determinant of children work. In this respect, Basu and Van specify a decreasing labour offer curve, possibly comprising two steady balances: one where the wages are raised and the children do not work - "good balance" -, the other, on the contrary, translating the existence of weak profits and a strong incidence of the hard-working children - "bad balance". Moreover, when the latter prevails, the prohibition of the child labour can lead, all things equal elsewhere, to the restoration of the "good balance".

Then, several empirical researches seem to confirm the significant impact of poverty on the child labour. Thus, Basu and Tzannatos (2003) quote many micro or macro-economic study, recently carried out in Asia, showing a close connection between the increase in the standard of living of the households and the reduction of the child labour. In this respect, the approach of Edmonds (2005), founded on panel data in Vietnam, suggests a significant reduction of the hardworking children when the economic status of the families improves. In the same way, in West Africa, several empirical investigations - Blunch and Verner (2000), Grootaert (1998), Diallo (2001), Lachaud (2008), Meka'a, C. B. and Ewondo Mbebi, O, (2015)-, highlight a positive relation between the poverty and the children work.

However, other research tends to question the validity of the assumption of the luxury axiom. For example, Canagarajah and Coulombe (1997) in Ghana, Nielsen (1998) in Zambia, and Maitra and Ray (2000) in Peru, note the absence of significant relation between the poverty of the households and the participation of the children in the labour market. In the same way, it is sometimes said that the rise of household's life level implies a better access to the labour market, including for the children (Bhalotra, Heady, 2003).

Secondly, the non-linearity of the relation between the household's incomes and the participation of children in the labour market seem insufficiently discussed in the literature (Lachaud, 2008). However, several elements suggest the interest of such an approach. First of all, the model of Basu and Van implies a discontinuous structure of the relation between the child labour and the household's living standard. Indeed, children labour offer is null as long as household's resources is greater than the threshold of subsistence, but increases appreciably when families profits are low. Then, the absence of taking into account of non-linearity between the child labour and the household's resources can skew the conclusions of certain econometric analyses, the linear approaches homogenize disparate situations. For example, in the developing countries, the agro-ecological zones diversity can generate different sensitivities between the children labour and the household's income. Lastly, the rare studies taking of account non-linearity between the child labour and the household's incomes produce interesting teachings. For example, at the macro-economic level, Fallon and Tzannatos (1998) observe that the incidence of the child labour of 10-14 years is very high - 30-60 percent - in the countries whose GDP per capita is lower than 500 dollars U.S. (at the prices of 1987), declines very quickly - 10-30 percent - when its lies between 500 and 1000 dollars U.S., then decreases slightly on higher levels of GDP per capita, in particular in the zone of the 1 000-4 000 dollars U.S. To a certain extent, the share of agriculture in the GDP seems in relation to the incidence of the child labour. In the same way, at the micro-economic level, the study of Edmonds (2005), founded on panel data in Vietnam, shows for 1993 that below the level of subsistence - the equivalent of a purchasing power of 2100 calories per day - the child labour is relatively inelastic compared to the expenditure per capita. On the other hand, beyond this threshold, the proportion of households having a living standard close to the poverty line is significant, and the decline of the child labour accelerates. Moreover, it is shown that the progression of the expenditure per capita between 1993 and 1998 explains 10-80 percent of the decline of the child labour which occurs in the households having escaped with poverty. 
Thirdly, whereas the spatial distribution of the activities and economic opportunities is of first importance for the target of actions in favour of the most underprivileged groups, the space dimension of the child labour is imperfectly taken into account in many econometric studies. Indeed, the majority of the empirical investigations devoted to the examination of the determinants of the child labour - jointly or not with schooling -, in particular the impact of the level of the households, apprehend the spatial distribution of the economic activities compared to a specification of the rural and urban area. In this respect, the differentiation of the area takes place is by the introduction of a binary variable (Ray, 1999; Maitra, Ray, 2000; Rosati, Rossi, 2001; Ray, 2001;Ray, Lancaster, 2003; Ewondo Mbebi, O. 2018, Abou Pokou E. 2019), are by considering equations specific to each area (Grootaert, 1998;Nielsen, 1998; Blunch, Verner, 2000; Diallo, 2001; Shafiq, 2007; Cockburn, Dostie, 2007). More rarely, of the fixed effects according to areas (Canagarajah, Coulombe, 1997; Rosati, Tzannatos, 2006), the provinces (Duryea, Arends-Kuenning, 2003; Dammert, 2007; Lachaud, 2008) or the communes (Edmond, 2005) are introduced into the analysis. In truth, this report led to two observations. First of all, according to countries, the taking into account of the determinants of the child labour according to the area - rural and urban - is necessary, but probably insufficient insofar as it is likely to homogenize dissimilar situations. Indeed, in many developing countries, the diversity of the agro-ecological zones or the various types of cities can generate sensitivities different between the economic activity from the children and the characteristics of the households, which can skew the conclusions of too aggregate econometric approaches.

This brief literacy review shows that the micro-econometric multilevel and the spatial macro-econometric models are appropriate when the data structure is hierarchal with spatial possible interactions.

\section{Data Structure and Methods of Analyze}

The presentation of the data structure helps to justify the use of both micro-econometric multilevel modelling and spatial macro-econometric modelling.

\subsection{Data Structure}

This research is based on data from the Third Survey among Cameroonian Households (ECAM3) carried out by the National Institute of Statistics-Cameroon (INS), whose presentation can be categorized into three namely: Fields, units and strata of the survey, Frame and Purpose of investigation and non-response rate.

\subsubsection{Fields, Units and Strata of the Survey}

The statistical unit is the household usually defined (INS, 2008) as a set composed of one or more people (socioeconomic unit), having a blood tie of marriage or not living in one or more of the same housing concession (this set of dwellings as housing unit), pooling all or part of their resources to meet the current expenditures, usually taking their meals together, and recognizing the authority of one person as householder (or reference person).

The ECAM3 is performed by the INS during the period September to December 2007. It covered the entire country and is representative by region and both rural and urban areas. Indeed, strata of the survey on child labour are exactly 32 : 12 urban strata (the two cities Yaoundé and Douala-Cameroon-and urban strata of each of the ten regions); 10 semi urban strata (a stratum by region); 10 rural strata (one per region).

The urban stratum consists of major cities (at least 50000 inhabitants). Semi-urban stratum consists of small towns from 10000 to less than 50,000 inhabitants and the rural stratum consists of small towns with less than 10,000 inhabitants. A post-stratification was carried out - for the analysis - to distinguish urban strata in the strict sense of the other strata - say rural wider (INS, 2008). A child can only belong to one and only one region or one area, which bases the data hierarchal stricture.

\subsubsection{Frame}

The frame used - made up of enumeration areas (EAs) from the last general census of population and housing (RGPH3) which dates from November to December 2005 - was provided by the Central Bureau of Census and Studies Population (BUCREP). The sampling design is applied to two types stratified random degree; the strata are those defined above. First degree in each stratum is pulled EA and a second degree is a sample of households selected from each EA in the first degree - 12 in Yaoundé and Douala and 18 elsewhere. In total 12609 households were sampled from 742 EAs.

This sampling procedure, common to most household surveys, cannot exclude the possibility of spatial dependence information (Lachaud, 2007). Indeed, the data can be correlated within a group - a stratum, for example because of unobserved factors shared by individuals or households belonging to the latter. For example, the incidence of child labour in the same stratum is probably similar, since they are likely to share many characteristics. Therefore, the sampling procedure used implies that the observations of the same group may be more homogeneous than those randomly selected, which violates the assumption of independents observations underlying the classical statistical analysis.

As a result, taking into account the conventions No. 138 and No. 182, and the resolution concerning statistics on child labour, the children's age groups considered in the study is 5-17 years. Thus, 5,999,053 children in this age group $2,441,181$ (41 percent) were classified in the group of economically active children.

In total the hierarchical structure of data from the ECAM3 and the spatial dependence can be taken into account by both Micro-econometric multilevel modelling Macro-econometric spatial Modelling (Lachaud, 2007). 


\subsection{Micro-Econometric Multilevel Approach}

The framework for multilevel analysis provides a first appropriate approach to reflect the hierarchical structure of data previously described (Goldstein, 2003; Gelman, Hill, 2007). First, the modelling in terms of random constants and random coefficient takes into account on the one hand, the greater homogeneity of observations within a group and consider that the level of children's labour incidence varies between strata - regions - and, secondly, to allow variation of the effect of certain variables according to the last. In this context, the econometric estimation of determinants of child labour is based on a logit model, expressed by the following general functional form:

$Y_{i j}^{*}=\beta_{0}+\mu_{0 j}+\mu_{m j}+X_{i j} \beta+\alpha_{0} D_{i j}+\sum_{h=1}^{4} \alpha_{h} D_{i j h}+\varepsilon_{i j}$

Where $\mathrm{Y}_{\mathrm{ij}}^{*}$ is a continuous latent variable - unobservable - related to the indicator of economic status of children in the household $i$ in stratum $j$ - region $(Z D)$ - such as:

\section{$\mathrm{Y}=\left\{\begin{array}{l}1 \text { if }=\mathrm{Y}_{\mathrm{ij}}^{*}>0 \quad \text { participation on labour market } \\ 0 \text { if }=Y_{\mathrm{ij}}^{*}<0 \text { non }- \text { participation on labour market }\end{array}\right.$}

The constant consists of two terms $\beta_{0 j}=\beta_{0}+\mu_{0 j}$, $\beta_{0}$ the fixed part is common to all regions, while $\mu_{0 j}$, the component is specific to each strata is the random part. The random effect represents unobserved local factors for children located in the same stratum (region), and participation rates of children in the labour market in the same stratum are correlated because they share the same random effect. The error term $\varepsilon_{\mathrm{ij}}$ follows a logistic distribution with zero mean and variance $\pi^{2} / 3$.

In this study, we consider that the effect of environment $j$ on the incidence of child labour varies from one region to another, instead of remaining fixed as the last. $\mu_{\mathrm{mj}}$ reflects the fact that the coefficient on $\mathrm{m}$ varies with the stratum $\mathrm{j}$, which characterizes a class of models with random coefficients.

According to previous studies (Abou Pokou E. 2019, Diallo, 2001; Lachaud, 2007; INS, 2008), and available data, the factors $\left(\mathrm{X}_{\mathrm{ij}}\right)$ that may explain child labour in Cameroon have been grouped into three classes: the characteristics of the child, characteristics of the household head and family environment. The characteristics of the child include the child's age, sex, relationship with the household, educational level, parental survival (children fatherless or motherless), and nationality. The characteristics of the household head concerning gender, marital status, level of education, religion, the presence or absence of a disability and socioeconomic group. The family environment for household characteristics involving the following variables: household size combined with number of children aged 0-4 years for those aged 5-17 years and seniors over 55 years of consumption expenditure per capita household.

Household's income per capita need special attention. For this purpose, the functional form (1) includes consumption expenditure per capita. Note that this determinant of child labour is testing the impact of small changes in adult income, and to a lesser extent, the luxury axiom of Basu and Van (1998). The quadratic effect of consumer spending per capita is also considered by its square.

This research aims to capture the discontinuities by modelling consumer spending per capita according to the regression approach by "spline". From this perspective, the study proposes to model consumer spending per capita household so that the coefficients - or marginal effects - indicate change in the rate of change in the incidence of child labour, following a change in consumption expenditure corresponding to a segment of adult resources, the latter being generated in terms of quintiles of the distribution. This technique involves a continuity of the function, that is to say the join of the various segments of spending thresholds. The Wald statistic tests the null of simultaneous different coefficients of consumption expenditure per capita - linear or nonlinear restrictions attached to set of coefficients. Thus, according to Suits, D.B., Maso, A., and Chan, L., (1978) the functional form (1) $D_{i j h}=D_{i j}-Z_{h}$ means that if $D_{i j}>Z_{h}, Z_{h}$ being different quintiles $h$ threshold. For example, if $D_{i j}>Z_{1}, D_{i j 1}=D_{i j}-Z_{1}$. Similarly, $D_{i j 4}=D_{i j}-Z_{4}$. As a result the codification of consumption expenditure per capita is made of the extent that each coefficient inherent to a quintile $D_{(h+1)}$ of consumption per capita is the change in slope relative to the segment, and with $h \geq 1$ and $D_{1}$ the first quintile threshold $D_{i j 2}$. Therefore, the slope of $\mathrm{D}_{\mathrm{ij} 1}$, for example, is $\alpha_{0}+\alpha_{1}$, and the slope of that is of consequence. Joint Wald test to check if the slope of the function is constant, that is $\alpha_{1}+\alpha_{2}+\alpha_{3}+\alpha_{4}+0$.

This approach involves the development of appropriate tests. First the partition coefficient of variance (PCV) can be evaluated. This is the proportion of total residual's variance attributed to regions: $\mathrm{PCV}=\sigma_{\mathrm{uo}}^{2} /\left(\sigma_{\mathrm{uo}}^{2}+\sigma_{\mathrm{e}}^{2}\right)$ where $\sigma_{\mathrm{e}}^{2}$ is the variance of the residual of the estimated function (variance between children). Indeed, with a logistic model, we can estimate PCV $=\sigma_{\mathrm{uo}}^{2} /\left(\sigma_{\mathrm{uo}}^{2}+3,29\right)$, where $3.29=\pi^{2} / 3$ (Rasbash, Steele, Browne, Prosser, 2005). Likelihood ratio tests is used to test significant differences across regions $\left(\sigma_{\mathrm{uo}}^{2}\right)$ and test whether the effects of urbanization vary by region $-\sigma_{\mathrm{uom}}^{2}$ and $\sigma_{\text {uo }}^{2}$ different from zero. Moreover, the Fisher test used to assess the individual significance of each coefficient.

Interpretation of results requires the sign of each estimated coefficient which gives the sense of the considered factor's impact on children probability to work.

\subsection{Macro-Econometric Spatial Modelling}

The spatial econometrics seeks to address the two major characteristics of spatial data that is spatial autocorrelation refers to the lack of independence between geographical observations and spatial heterogeneity that is related to the differentiation in the space of variables and behaviors. The present study focuses on the spatial dependence of observations and hence the autocorrelation. The spatial dependence of observations in the sample can be defined as the observation in a localized spatial unit "p" depends on other observations inherent to spatial units " $k$ " different from "p". 
Indeed, on the one hand, the collected information associated with spatial units can replicate measurement errors, administrative boundaries do not reflect the actual process may be apprehended. For example, the incidence of child labour in the spatial unit "p" can be linked to another spatial unit " $k$ " if the active members of households living in "p" where the information was collected-have access to low-paying jobs in " $k$ ". On the other hand, the spatial dimension of economic activities can be an important aspect of the modelling, when prevailing effects of spatial interaction (between considered units), hierarchies of location and spatial externalities. Thus, the economic dynamism of a city of a spatial unit can be explained by the proximity of another that includes a major urban center. When these situations prevail, the coefficients of the least square's estimates are biased and not efficient (Lachaud, 2007; Anselin, 1988, Le Gallo J., 2002, 2004). In the study, the spatial econometric approach captures the spatial autocorrelation using regression models with spatial autoregressive error and mixed. Regarding the spatial error model, spatial dependence is stipulated as a disturbance through an auto-regressive variable, and involves a formalization using the following equation:

$\mathrm{E}=\mathrm{X} \beta+\varepsilon$

Where $\varepsilon=\lambda_{\mathrm{s}} \mathrm{W} \varepsilon+\zeta$ and $\zeta \sim \mathrm{N}\left(0, \sigma^{2} \mathrm{I}_{22}\right.$

Here $\mathrm{E}$ is a column vector containing the ratio of employment of children aged 5-17 years for 22 observations (spatial units), while $\mathrm{X}$ is the matrix of explanatory variables in column (i) the average expenditure per capita consumption; ( ii) the quadratic effect of the average expenditure per capita consumption, (iii) the average years of education of household head, (iv) the proportion of women heads of household (v) The average number of children less than 5 years, and (vi) the average number of people over the age of 55 per household. Also $\beta$ is a column vector of coefficients of the explanatory variables raised; is a vector $(22.1)$ as $\varepsilon_{j} \sim \operatorname{iid}(0, \sigma) \lambda_{s}$ the autoregressive coefficient

representing the degree of spatial autocorrelation between the residuals of the regression, $\mathrm{W} \varepsilon$ the random term is spatially shifted, and $\zeta$ the error term uncorrelated and homoscedastic. Moreover, $\mathrm{W}$ is inherent in a spatial weights matrix, standardized - from the lines - adjacency-order, formulated in terms of the common borders of the 22 spatial units.

Regarding the auto-regressive model, spatial autocorrelation is taken into account by a lagged endogenous variable in equation.

$\mathrm{E}=\rho \mathrm{WE}+\mathrm{X} \beta+\varepsilon$

Where $\rho$ spatial autoregressive parameter indicating the importance of the interaction that exists between observations is $E_{j}$; WE the lagged endogenous variable for the spatial weight matrix $\mathrm{W}$, it should be noted that the introduction of the lagged endogenous variable for unit i means that the observation $E_{j}$ is partly explained by the values taken by neighboring spatial units. WE is interpreted as the average values of $\mathrm{E}$ on neighboring observations of $\mathrm{i}$, $\mathrm{W}$ is standardized.

The estimates are based on the maximum likelihood, and the null hypothesis of the form $\mathrm{H}_{0}: \rho=0$ can be verified using several tests among which the Lagrange multiplier and likelihood ratio.

\section{Results and discussion}

\subsection{Teachings of the Multilevel Micro-Econometric Approach}

Table 1 shows the estimated coefficients of the logit multilevel model of child labour determinants using likelihood maximum with incomes taken into "splines". It is interesting to present area and region random effects, and household income's per capita before interpreting the other determinants.

\subsubsection{Area and Region Random Effect, Child Labour and Household Incomes}

The spatial dimension of child labour is highlighted regardless the configuration of the variable inherent in the income of adults. First, the likelihood ratio test can be used to test whether the effect of environment/area varies among regions. The null hypothesis to be tested is Ho: $\sigma_{\mathrm{uo}}^{2}=\sigma_{\mathrm{uom}}^{2}=0$. The estimated likelihood ratio Statistics test is $\mathrm{LR}=$ 184.2236 with 2 degree of freedom is greater than the tabulated chi- 2 at $5 \%$ with 2 degree of freedom is 5.99 . Which means the existence of significant differences in children's participation in the labour market by region and that the effect of environment varies by region. The employment rate for children in the same region are correlated because they share the same random effect $u_{j}$, that represent unobserved local factors. Then, we observe that the partition coefficient of variance VPC - intra-region correlation coefficient- is $1.523 /(1.523+2.29)=0.3994$. About 40 percent of the total variance of the residuals is due to differences among regions. Finally, the coefficient for the environment is positive and varies by region with an estimated variance $0.546(0.255)$. 


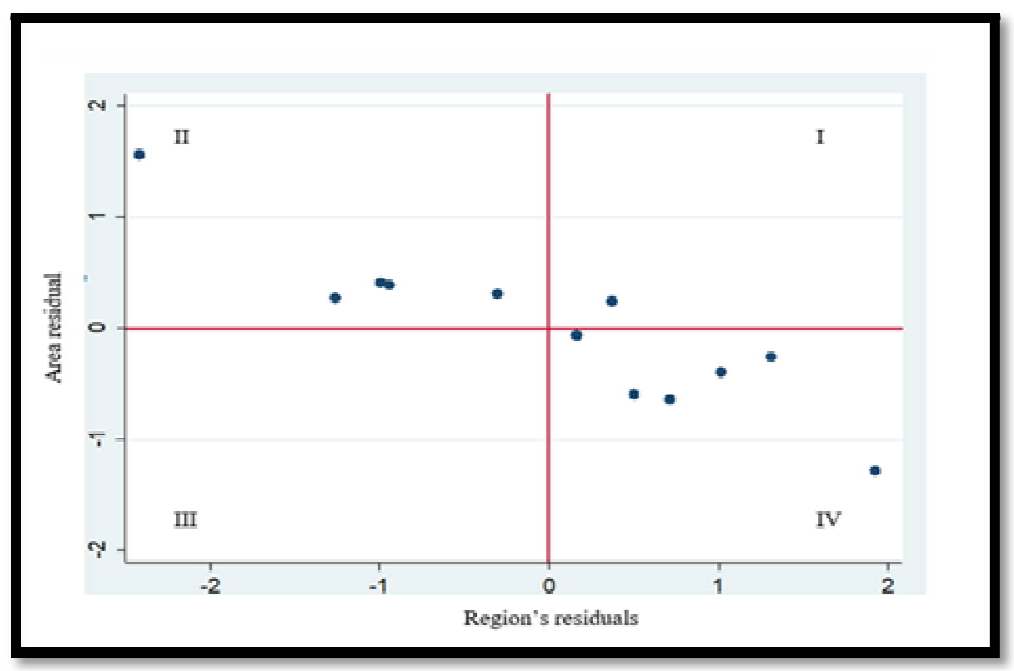

Figure 1: Residual of Region Vs Area

Source: ECAM3, 2007, Following Our Calculations

The covariance of random effects in the range of -0.832 indicates a negative relationship between the random effects in the region and environment/ area. The strength of this correlation is noted through their correlation coefficient is about -0.91 near unity in absolute value. This is also illustrated by Figure 8 below. It is found that when a child has a high random region (positive) it generally has a medium low (negative) and vice versa. Consequently, the points representing the medium as a function of residue of the second hierarchical level (regions) are found in quadrant II (upper left) and IV (bottom right). Quadrants I (top right) and III (bottom left) remained virtually empty.

Econometric estimates show the nonlinearity of the impact of household consumption expenditure per capita and therefore income per capita - on the early development of children in the labour market. In this regard Lachaud (2008) points out that the logistic estimation to calculate the relative risk - likelihood ratio - which is the exponential of the regression coefficient. It represents the multiplicative effect of a unit increase in the regressor on the initial ratio of opportunity (if the variable is continuous) or odds ratios compared to the reference category (if the variable is categorical).

In this context information about the multilevel hierarchical model contained in Table 1 show that adults income coefficient is negative and statistically significant. Its relative risk is equal to 0.994 , meaning that an increase in earnings of adults in the household of F CFA 10,000 induced, all things being equal elsewhere, a lower risk of child labour by a multiplicative factor of 0.994 . Similarly, the rule of division by four of the regression coefficients (Lachaud, 2008) indicates a reduction of 0.158 percent $(-0.006322$ / 4$)$ of the probability of child labour resulting from adults' earnings increase in a unit (10, $000 \mathrm{CFA})$.

\begin{tabular}{|c|c|c|c|}
\hline Variables & $\boldsymbol{\beta}$ & $\mathbf{t}^{2}$ & Risque relatif ${ }^{3}$ \\
\hline Child & & & \\
\hline Age & 0,713 & $16,77 * * *$ & 2,040 \\
\hline$(\text { Age })^{2} / 100$ & \multirow{2}{*}{ Region's residuals } & $-9,75^{* * * *}$ & 0,163 \\
\hline Sexe $^{4}$ & & 0,54 & 1,021 \\
\hline Relation with households ${ }^{5}$ & 0,065 & 1,38 & 1,067 \\
\hline \multicolumn{4}{|l|}{ Instruction level ${ }^{6}$} \\
\hline Primary & $-0,022$ & $-0,34$ & 0,978 \\
\hline Secondary 1st cycle & $-0,651$ & $-7,52^{* * * *}$ & 0,522 \\
\hline Secondary 2nd cycle and more & $-1,030$ & $-7,04^{* * *}$ & 0,357 \\
\hline Parental suvivance ${ }^{7}$ & 0,162 & $2,38^{* *}$ & 1,176 \\
\hline Natinality $^{8}$ & $-0,243$ & $-1,24$ & 0,784 \\
\hline \multicolumn{4}{|l|}{ Household } \\
\hline Sexe $^{9}$ & 0,040 & 0,80 & 1,041 \\
\hline \multicolumn{4}{|l|}{ Marital status ${ }^{10}$} \\
\hline Married single & $-0,587$ & $-2,82 * * *$ & 0,556 \\
\hline Mariéd polygame & $-0,875$ & $-2,09 * *$ & 0,417 \\
\hline Widow / Widower & 0,928 & 0,70 & 2,529 \\
\hline Divorcéd / Seperated & 0,511 & 0,45 & 1,667 \\
\hline Free union & 0,085 & 0,20 & 1,089 \\
\hline \multicolumn{4}{|l|}{ Instruction level ${ }^{11}$} \\
\hline Primary & $-0,061$ & $-1,12$ & 0,941 \\
\hline Secondary 1st cycle & $-0,218$ & $-3,11 * * *$ & 0,804 \\
\hline Secondary 2nd cycle & $-0,292$ & $-3,40^{* * *}$ & 0,747 \\
\hline Superior & $-0,384$ & $-3,05^{* * *}$ & 0,681 \\
\hline Religion $^{12}$ & & & \\
\hline Christian & $-0,038$ & $-0,76$ & 0,963 \\
\hline
\end{tabular}




\begin{tabular}{|c|c|c|c|}
\hline Musulman & $-0,200$ & $-2,62 * * *$ & 0,819 \\
\hline Handicap 13 & $-0,608$ & $-4,32^{* * *}$ & 0,544 \\
\hline \multicolumn{4}{|l|}{ Socio-economic group ${ }^{14}$} \\
\hline Private formal sector & 0,055 & 0,49 & 1,057 \\
\hline Agricol sector & 1,147 & $13,59 * * *$ & 3,149 \\
\hline Informal private sector & 0,307 & $3,76^{* * *}$ & 1,359 \\
\hline Unemployed & $-0,721$ & $-3,02 * * *$ & 0,486 \\
\hline Inactive / Retired & $-0,637$ & $-5,32 * * *$ & 0,529 \\
\hline \multicolumn{4}{|l|}{ Familial environment } \\
\hline \multicolumn{4}{|l|}{ Familial composition } \\
\hline Children of 0-4 & 0,019 & 1,04 & 1,019 \\
\hline Children of 5-17 & $-0,047$ & $-4,55 * * *$ & 0,954 \\
\hline Eldest 55 and over & $-0,044$ & $-1,29$ & 0,957 \\
\hline \multicolumn{4}{|l|}{ Houselod incomes - continuous } \\
\hline Household income per capita/ 10^4 & $-6,32 \mathrm{E}-03$ & $-1,91 * *$ & 0,994 \\
\hline$\left(\text { Household income per capita / } 10^{\wedge} 4\right)^{2}$ & $1,05 \mathrm{E}-05$ & 0,60 & \\
\hline \multicolumn{4}{|l|}{ Household income per capita « splines » } \\
\hline Household income per capita/ 10^4 & 1,55E-02 & $2,19 * *$ & 1,016 \\
\hline Variables & $\beta$ & $\mathbf{t}^{2}$ & Risque relatif ${ }^{3}$ \\
\hline$\Delta \mathrm{D} 1$ & 2,16E-02 & $1,31 *$ & 1,022 \\
\hline$\Delta \mathrm{D} 2$ & $-1,30 \mathrm{E}-03$ & $-0,12$ & 0,999 \\
\hline$\Delta \mathrm{D} 3$ & $1,07 \mathrm{E}-04$ & 0,01 & 1,000 \\
\hline$\Delta \mathrm{D} 4$ & $-4,07 \mathrm{E}-03$ & $-0,66$ & 0,996 \\
\hline Region's random effect & $-7,356$ & $14,65^{* * *}$ & -- \\
\hline Area's random effect & 0,922 & $3,93 * * *$ & -- \\
\hline$\sigma_{\mathrm{uo}}^{2}($ standard error $)$ & \multicolumn{3}{|c|}{$1,523(0,683)$} \\
\hline$\sigma_{\mathrm{um}}^{2}($ standard error $)$ & \multicolumn{3}{|c|}{$0,546(0,255)$} \\
\hline$\sigma_{\text {uom }}^{2}$ (standard error) & \multicolumn{3}{|c|}{$-0,832(0,402)$} \\
\hline VPC & \multicolumn{3}{|c|}{0,3994} \\
\hline Wald & \multicolumn{3}{|c|}{2191.97} \\
\hline $\mathrm{N}$ & \multicolumn{3}{|c|}{17550} \\
\hline
\end{tabular}

Table1: Estimated Coefficients of the Multilevel Logit Model of Children (5-17 Years) Work1 Determinants- Cameroon 2007

(1) The dependant variable is equal to one when a child 5-17 participate in child labour and is equal to zero if not; (2) « Two-tailed » probability that the coefficient is equal to zero. t is the ratio of the parameter $\beta$ and its standard error; (3) The relative risk or chance ratio is given by the exponential of each estimated coefficient. It represent a multiplicative effect of an increase by one unit of the given explanatory variable if the variable is continuous or relative chances compared with the referenced category if the variable is categorical ; (4) Base = Male ;(5) Base $=$ Isn't a native child of the household; (6) Base = Sans niveau; (7) Base = The two parents are alive; (8) Base =Stranger ; (9) Base =Male; (10) Base = Bachelor ; (11) Base =Null level ; (12) Base = Animistic / Other / without religion; (13) Base =The household is disable; (14) Base =Public sector; (15);(16).

Source: ECAM3 2007

Taking into account the nonlinearity of income is appropriate that the square of the coefficient of adult's income is not significant. Indeed, modelling adult's income in "splines" indicates that when adult earnings are below the threshold of the first quintile of the distribution increases to $10000 \mathrm{CFA}$, the rate of change of labour incidence children increases by a multiplicative factor of 1.016. Another way to interpret the coefficient of 0.0155475 - statistically significant - is to indicate that for the first income quintile, the rate of change in the probability of child labour is 0.389 percent (according to rule fourfold), where income adults range from 10,000 F CFA. Moreover, there is a positive and meaningful change in the rate of variation of children's participation in the labour market in when adult earnings per capita exclude the equivalent threshold in the first quintile. This result agrees with that of Lachaud (2008) in the case of Madagascar.

The model used to explain the propensity of children participation in the workforce. Explanatory factors of child labour can be analyzed according to the categories discussed in the explanatory variables in multilevel model.

\subsubsection{Child labour and other determinants}

Analysis of the characteristics of children revealed that their propensity to be part of the economically active population increases with age. This can be explained by the fact that the spots are made by children of manual tasks, they require physical exertion which is more possible as far as the child grows. However, the negative value of the coefficient related to the square of age reported to one hundred shows that this propensity believes strongly in the early years and then grows less strongly and then decreases.

The analysis by level of education of the child indicates that level without reference to children, those with at least junior high less likely to be on the job market. Thus, schooling holds back child labour. 
Parent's survival favors early child labour. Indeed, in reference to children whose both parents are alive, orphans of both parents have a greater propensity to be engaged in economic activities. This result reveals the important role of parents in supervising their children.

There is an absence of discrimination by sex, nationality and relationship to the householder. Here we find the same results as the INS (2008, pp. 103-104) in the national report in child labour in Cameroon.

Regarding the characteristics of the household head only gender does not influence the early children entry on the labour market.

As for marital status is noted that children whose head of household is married monogamous or polygamous are less likely to work compared to children whose household head is single.

The educational attainment of household head appears as an important factor in understanding children's participation in economic activities. With reference to households who are low level, those with at least junior high are less willing to involve children early in economic activities. The effect of education of household is joined and confirmed the results of Diallo (2001) in the case of the Ivory Coast. According to the INS (2008, p.105) The improvement of education also leads to the reorientation of activities towards sectors employing fewer children, and facilitates access to financial markets, a possible source of funding education of children improving their welfare.

The religion practiced by the household head is not neutral in the activity status of the child. Children whose household is Muslim would be less likely to work early compared to children whose household head is animistic or does not have any religion everything equal elsewhere.

Children whose family head is disabled is less likely to find themselves on the labour market compared to children whose household head is not disabled everything equal elsewhere. To this end householders' victims with disabilities may have a significant capital in Bourdieu.

The socio-economic group is not without influence on the development of child labour. Children whose head of family practices in the agricultural sector and the informal private sector have a high propensity to be early at work in reference to those whose household heads engaged in the public sector. Children whose households are unemployed, inactive or retired are less likely to work. Among the characteristics of the households only gender does not influence the early children work.

\subsection{Teachings of the Spatial Macro-Econometrics Approach}

The spatial macro-econometric approach takes into account the spatial dependence of the observations, although the aggregation of these observations (Lachaud, 2007) limits the understanding of the impact of individual factors - for example, the structure of parental education may influence the rate of employment of children at micro-economic level, without being seen in terms of average per spatial unit in this study. Moreover, in this our study, the number of observations is reduced to 22 spatial units according to the considerations made to regarding the topology of the spatial configuration of Cameroon inherent in the available data. The macro-econometric spatial estimations check the robustness of certain items previously highlighted. Table 1 shows the coefficients of the regression models with spatial autoregressive error and testing for the 22 spatial units, the relationship between, on the one hand, the rate (per spatial unit) of employment of children 5-17 years and, on the second hand, a set of parameters generated by the third Cameroonian survey.

First, we note that for the spatial autoregressive model that the coefficient $\rho$ of the variable spatially dependent is significant. In addition, the Breusch-Pagan statistic shows that this model is free of heteroscedasticity at 5 percent, which implies a constant variance of residuals. In fact, in the model with spatially varying delayed, the Lagrange multiplier test-LM (delay) inherent in the standardized spatial weight matrix is significant - $3.482(0.062)$ - unlike the likelihood ratio - LR (delay) 2.260 (0.133), which may lead to assume that the spatial dependence has been properly taken into account by the parameter.

Moreover, the spatial error model does not show the presence of spatial autocorrelation since the coefficient of the random variable spatially dependent delay is not significant. Comparing the log likelihood criteria shows that the best model is the model with spatially varying delayed. Therefore, comments are made in relation to the model (2) spatial autoregressive. Moreover, the statistic calculated Jarque-Bera is 1.192 less than the tabulated value (5.99) at two degree of freedom at $5 \%$. We accept the null hypothesis of the test the assumption of normality of errors.

Second, the model (2), shown in Table 1 indicates a negative and significant (-0.034) coefficient of consumption expenditure per capita. Therefore, all things being equal, depending on the model (2), the increase in per capita consumption expenditure of households reduced the proportion of economically active children and hence the propensity of children to participate in the labour market. In this regard, the evaluation of the mid-point elasticity produces a value of -1.553 .

\begin{tabular}{|c|c|c|c|c|}
\hline Dependent Variable & \multicolumn{3}{|c|}{ Ratio of Average Employment of Children (5-17years) } \\
\hline & \multicolumn{2}{|c|}{ Model with spatial error ${ }^{1}$} & \multicolumn{2}{c|}{ Model spatially autoregressive ${ }^{2}$} \\
\hline Parameters & $\mathrm{B}$ & $\mathrm{t}^{3}$ & $\beta$ & $\mathbf{t}^{3}$ \\
\hline Constant & 0,599 & $3,535^{* * *}$ & 0,696 & $3,998^{* * *}$ \\
\hline Consumption expenditure per capita $^{4}$ & $-0,047$ & $-3,268^{* * *}$ & $-0,034$ & $-2,246^{* *}$ \\
\hline $\begin{array}{c}\text { Consumption expenditure per capita } \\
\text { squared }\end{array}$ & 0,001 & $2,486^{* *}$ & 0,001 & $1,651^{*}$ \\
\hline Years of education of household $^{6}$ & $-0,005$ & $-0,273$ & $-0,016$ & $-0,903$ \\
\hline
\end{tabular}




\begin{tabular}{|c|c|c|c|c|}
\hline Ratio women household heads ${ }^{7}$ & 0,601 & $1,701 *$ & 0,555 & $1,653 *$ \\
\hline $\begin{array}{c}\text { Nombre de personne de plus de } 55 \\
\text { ans }^{8}\end{array}$ & 0,335 & 0,959 & 0,181 & 0,596 \\
\hline$\lambda_{s}{ }^{9}$ & $-0,029$ & $-0,149$ & -- & -- \\
\hline$\rho^{10}$ & -- & -- & $-0,218$ & $-1,641^{*}$ \\
\hline Log likelyhoo 11 & \multicolumn{2}{|c|}{19,836} & \multicolumn{2}{|c|}{20,961} \\
\hline \multicolumn{5}{|c|}{ Heteroscedasticity: } \\
\hline Spatial Breusch-Pagan ${ }^{12}$ & \multicolumn{2}{|c|}{$3,339(0,648)$} & \multicolumn{2}{|c|}{$2,811(0,729)$} \\
\hline \multicolumn{5}{|c|}{ Spatial Dependence: } \\
\hline $\mathrm{LM}^{13}$ & \multirow{2}{*}{\multicolumn{2}{|c|}{$\begin{array}{l}1,674(0,196) \\
0,009(0,923)\end{array}$}} & \multicolumn{2}{|c|}{$3,482 *(0,062)$} \\
\hline $\mathrm{LR}^{14}$ & & & \multicolumn{2}{|c|}{$2,260(0,133)$} \\
\hline $\mathrm{N}$ (Spatial units) & \multicolumn{2}{|c|}{22} & \multicolumn{2}{|c|}{22} \\
\hline
\end{tabular}

Table 2: Regression Coefficients of the Determinants of Employment Ratio (Per Unit Space) of Children (5-17 Years) - Cameroon 2007

(1) Model (1) has a random term spatially dependent; (2) Model (2) refers to the spatial autoregressive model incorporating a spatially dependent variable delay; (3) probability "two-tailed" that the coefficient is zero. $\mathrm{T}$ is the ratio between the $\beta$ and the standard error; (4) consumption expenditure per capita per spatial unit in F CFA / 10,000 per month; (5) quadratic effect of consumption expenditure per capita; (6) Average years of education of household head; (7) Ratio of women heads of households; (8) number of people aged over 55 years; (9) $\lambda_{s}$ is the coefficient of $(\mathrm{Wr})_{j}$; (10) is the coefficient; (11) The maximum likelihood criterion - the best model is the one for which the value is greater; (12) heteroscedasticity test spatial Breusch-Pagan; (13) the Lagrange multiplier test with error and delay; and (14) the likelihood ratio test.Note: ${ }^{\prime * * * 1}=$ significant at 1 percent, ${ }^{\prime * * 1}=$ significant between 5 per cent ${ }^{\prime * 1}=$ significant at 10 percent. Source: ECAM3, 2007.

In other words, the macro-econometric estimation with spatial autoregressive model suggests that, given the level of education of the household head, the proportion of female heads of household and social capital - average people over the age of 55 per household - (variables assumed unchanged), an increase of one percent of regional income per capita adults induces a reduction of about 1.55 percent ratio - per unit space - children 5-17 years economically occupied.

Third, the non-linearity of the impact of income per capita household on child labour is checked for spatial units, since according to the model (2) spatial autoregressive regression coefficient of per capita income squared is significant 10 percent.

Fourth, spatial incidence of child labour is related to the ratio of women heads of households. Indeed, the latter coefficient is positive and significant. In particular, the labour market participation of children is much higher than the ratio of women heads of households is high. Moreover, the elasticity calculated midpoint is 0.42 which means that, all things being equal, a one percent increase in the ratio of women heads of households leads to an increase in the ratio of economically active children 0.42 percent. This could be explained by the particularly difficult living conditions which they face.

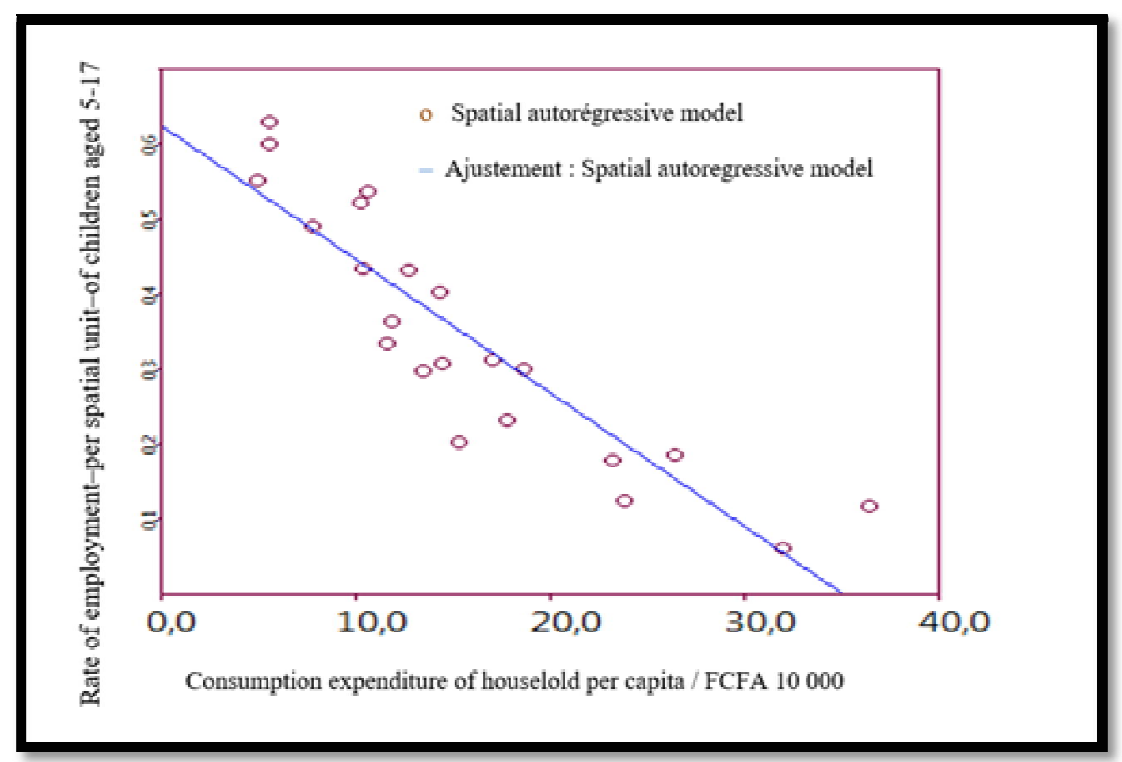

Figure 2: Impact of Consumer Spending-by Spatial Unit-Per Capita on the Employment Rate of Children Aged 5-17

Source: ECAM 3, 2007 
Figure 2 reproduces the predicted employment rate - per spatial unit - of children 5-17 years depending on consumption expenditure per spatial unit per capita. It illustrates the inverse relationship between earnings / income of adults and children's participation in the labour market. The linear fit to the spatial autoregressive model has a negative slope of -0.0177 . This means that all else being equal, the ratio of employment of children decrease 0.0177 when consumption expenditure per capita household increased by 1 percent.

\section{Conclusion}

The present research examines the hypothesis of non-linearity of the impact of household's incomes per capita on child labour and consider the appropriateness of the econometric estimates taking into account the spatial dependence of the observations in Cameroon. To come to these concerns a multilevel micro-econometric modelling and a spatial macro econometric modelling where required.

At the end of this analysis, results of econometric estimates suggest the influence of several factors on child labour: children's characteristics, household's characteristics, number of people over age 55 in the family. Estimations reveals that it exists significant differences in children's participation in the labour market by region, the area and region random effects are negatively correlated; The differentiation of behavior and thus the nonlinearity is revealed by household's income per capita taken into "spline" in the early children work. Indeed, when adult earnings are below the threshold of the first quintile of the distribution increases to $10000 \mathrm{CFA}$, the rate of change in the incidence of child labour decreases by a multiplicative factor of 1.016. However, there is a positive and meaningful change in the rate of change in work when household's resources excluding the threshold equivalent in the first quintile of income distribution, the relative risk being 1.022; econometric estimates suggest the influence of other factors on child labour: child characteristics, characteristics of the household head the number of people over 55 years in the household.

The spatial dependence of the observations is properly taken into account by an autoregressive spatial model. The income per capita coefficient is significant and negative; this confirms the "luxury axiom" of Basu and Van on aggregated data i.e. the increase in household's consumption expenditure per capita reduces the proportion of children economically active. The non-linearity of the impact of the income per capita of the households on the child labour is checked at the level of the spatial units The space incidence of the child labour is in relation with the ratio of female households, the elasticity calculated at the average point is 0,42 what means that, an increase in one percent of the ratio of the female households implies an increase of the child labour ratio of 0,42 percent.

Therefore, the significant reduction of child labour depends on the household's income increase of the poorest households. Moreover, the effects can vary by region and community, targeting actions depending on the spatial distribution of economic activities and opportunities is important.

\section{References}

i. Abou Pokou E. (2019) Re-Examination of the Determinants of Child Labour in Côte d'Ivoire, International Journal of Economics and Financial Research, Vol. 5, Issue. 2, pp: 26-35.

ii. Anselin, L. (1988). Spatial Econometrics: Methods and Models, Dordrecht, Kluwer Academic.

iii. Basu, K., Van, P.H., (1998). The Economics of Child Labour, American Economic Review, 88: 412-427.

iv. Basu, K., Tzannatos, Z., (2003). The Global Child Labour Problem: What Do We Know and What Can We Do? World Bank Economic Review, 17: 147-173.

v. Bhalotra, S., (2003). Child Labour in Asia and Africa, Bristol, Background Research Paper for the EFA Monitoring Report, mimeo, University of Bristol.

vi. Blunch, N-H., Verner, D., (2000). Revisiting the Link Between Poverty and Child Labour: The Ghanaian Experience. Washington, Policy Research Working Paper 2488, The World Bank.

vii. Canagarajah, S., Coulombe, H., (1997). Child labour and schooling in Ghana», Policy research working paper n/ 1844, World bank, Washington, D. C.

viii. Conventions No. 138 and No. 182 of the International Labour Organisation on Child work.

ix. Dammert, A.C. (2008) Child Labour and Schooling Response to Changes in Coca Production in Rural Peru, Journal of Development Economics, 86 (1), 164-80.

x. Decree No. 17 of 27 May 1969 related to Child Labour of Ministry and social laws in Cameroon.

xi. Diallo, Y., (2001). Les enfants et leur participation au marché du travail en Côte d'Ivoire, Bordeaux, thèse de doctorat ès sciences économiques, Centre d'économie du développement.

xii. Duryea, S., Arends-Kuenning, M., (2003). School Attendance, Child Labour and Local Labour Market Fluctuations in Urban Brazil, World Development, 31(7): 1165-178.

xiii. Edmonds, E.V., (2005). « Does Child Labour Decline with Improving Economic Status? », Journal of Human Resources, 40(1): 77-99.

xiv. Ewondo Mbebi, O. (2018). Les déterminants du travail des enfants au Cameroon: le rôle du milieu de résidence et du genre. Revue d'économie du développement, 2018/ 1 (Vol. 26), pp 5 - 52

xv. Fallon, P., Tzannatos, Z., (1998). Child Labour. Issues and Directions for the World Bank, Washington, Social Protection Human Development Network, The World Bank.

xvi. Gelman, A., Hill, J., (2007). Data Analysis Using Regression and Multilevel/ Hierarchical Models, New York, Cambridge University Press.

xvii. Goldstein, H. (2003), Multilevel Statistical Models, London, 3rd Edition, Arnold.

xviii. Grootaert, Ch. (1998). Child Labour in Côte d'Ivoire: Incidence and Determinants, Washington, mimeo, The World Bank. 
xix. INS, (2008), Rapport national sur le travail des enfants au Cameroun, Yaoundé Institut National de la statistique (INS).

xx. INS, (2009), Manuel des concepts et définitions utilisés qans mes publications statistiques officielles au Cameroun.

xxi. Lachaud, J.-P., (2007). Les déterminants de l'inactivité économique et de la non-scolarisation des enfants aux Comores et à Madagascar. Existete-t-il une courbe de Kuznets?, Pessac, Document de travail 140, Lare-Efi-Ged, Université Montesquieu-Bordeaux IV.

xxii. Lachaud J.-P., (2008). Le travail de enfants et le revenu des ménages à Madagascar : Dépendance spatiale et non linéarité, Groupe d'économie du développement-GED LARE-EFI -Université Montesquieu-Bordeaux IV, Document de travail DT/143/2008.

xxiii. Law No. 92/ 007 of 14 August 1992 on the Labour Code in Cameroon.

xxiv. Le Gallo J., (2002), Économétrie spatiale : l'autocorrélation spatiale dans les modèles de régression linéaire. Economie \& prévision, 2002/ 4 no 155, p. 139-157.

xxv. Le Gallo J., (2004), « Hétérogénéité spatiale », Principes et méthodes, Economie \& prévision, 2004/ 1 no 162, p. 151172.

xxvi. Maitra, P., Ray, R., (2000). The Joint Estimation of Child Participation in Schooling and Employment: Comparative Evidence from Three Continents, Oxford Development Studies, 30: 252-276.

xxvii. Meka'a, C. B., Ewondo Mbebi, O. (2015). Le travail des enfants : uniquement un problème de pauvreté ? Effet de la situation économique des ménages sur le travail des enfants au Cameroun en 2007. Travail et Emploi 143 (juilletseptembre 2015).

xxviii. Nielsen, H.S., (1998). Child Labour and School Attendance: The Joint Decisions, Aarhus, Working Paper 98-15, Centre for Labour Market and Social Research, Denmark.

xxix. Ray, R, (1999). How Child Labour and Child Schooling Interact with Adult Labour, Washington, Policy Research Working Paper 2179, The World Bank.

xxx. Ray, R., (2001). Child Labour and Child Schooling in South Asia: A Cross Country Study of their Determinants, Hobart, mimeo, September, University of Tasmania.

xxxi. Ray, R., Lancaster, G., (2003). Does Child Labour Affect School Attendance and School Performance?, Hobart, Discussion Paper (2003-04), University of Tasmania.

xxxii. Rosati, F.C., Rossi, M., (2001). Children's Working Hours, School Enrolment and Human Capital Accumulation: Evidence from Pakistan and Nicaragua, Rome, mimeo, Understanding Children's Work Project.

xxxiii. Rosati, F.C., Tzannatos, Z., (2006). Child Labour in Vietnam », Pacific Economic Review, 11 (1): 1-31.

xxxiv. Suits, D.B., Maso, A., Chan, L., (1978). Spline Functions Fitted by Standard Regression Methods, Review of Economics and Statistics, LX: 132-139. 